\title{
Análise das Transformações Ambientais no Entorno do Parque Estadual do Lajeado, Palmas - Tocantins
}

\section{Analysis of Environmental Transformations in the Surroundings of Lajeado State Park, Palmas - Tocantins}

Simonní Elias Furtado * Sandro Sidnei Vargas de Cristo **

\begin{abstract}
Resumo:
A pesquisa consiste na análise das transformações do uso do solo ocorridas entre os anos de 2000 a 2015 no entorno do Parque Estadual do Lajeado, localizado no município de Palmas, capital do estado do Tocantins, tomando-se como referência a observação da interferência das diferentes formas de ocupação ali instaladas. Para atingir o objetivo proposto utilizou-se técnicas de Geoprocessamento e Sensoriamento Remoto com a organização de um banco de dados via software Spring, do Instituto Nacional de Pesquisas Espaciais (INPE) e a interpretação de imagens dos satélites Landsat 5 e Landsat 8, apoiadas por diversos trabalhos de campo. Os resultados mostram que a expansão urbana e agricultura em larga escala são os principais responsáveis pela significativa transformação dos aspectos naturais da área.
\end{abstract}

\section{Abstract:}

The research consists of the analysis of the transformations of land use occurred between 2000 and 2015 in the surroundings of the State Park of Lajeado, located in the municipality of Palmas, capital of the state of Tocantins, taking as reference the observation of the interference of the different Forms of occupation installed there. In order to reach the proposed objective, Geoprocessing and Remote Sensing techniques were used to organize a database using the Spring software of the National Institute of Space Research (INPE) and the interpretation of images of the Landsat 5 and Landsat 8 satellites, supported by Fieldwork. The results show that urban sprawl and large-scale agriculture are primarily responsible for the significant transformation of the natural aspects of the area.
* MSc. em Geografia pela UFT e MSc. em Gestão e Auditoria Ambiental, pela Fundação Universitária Iberoamericana - FUNIBER. Servidora efetiva do IFTO/ Campus de Porto Nacional.

** Dr. em Geografia pela UFRGS. Professor Adjunto do Curso de Geografia-Campus de Porto Nacional da Universidade Federal do Tocantins-UFT
Palavras-chave:

Uso do Solo,

Unidades de Conservação da Natureza, Sensoriamento Remoto

Keywords:

Land Use, Conservation of Nature, Remote Sensing 


\section{INTRODUÇÃO}

$\mathrm{O}$ processo de construção da cidade de Palmas, capital do estado do Tocantins, desencadeou uma frenética ocupação das áreas nas proximidades da Serra do Lajeado, que se localiza a leste da cidade, caracterizando-se como uma porção geomorfológica elevada cuja sua disposição apresenta-se no sentido sul-norte acompanhada por aberturas de estradas de acesso e consequentemente maior supressão da cobertura vegetal.

Neste contexto, em 1989 o então governo do Estado foi alertado sobre a instabilidade ambiental da Serra do Lajeado, devido ao rápido processo de ocupação, o que colocava em risco, entre outros fatores, a manutenção da qualidade da água para o consumo dos habitantes da futura capital.

Diante deste quadro, foi promulgado o Decreto 213/89 criando a ARESL - Área de Representação Ecológica da Serra do Lajeado. Terminologia que não foi bem recepcionada pela Lei do Sistema Nacional de Unidade de Conservação - SNUC, sendo posteriormente transformada em APA - Área de Preservação Ambiental Serra do Lajeado (PLANO DE MANEJO APA LAJEADO, 2003, p. 25), que atualmente engloba o Parque Estadual do Lajeado, área da presente pesquisa.

De acordo com o Plano de Manejo da APA Serra do Lajeado (2003) esta área representa importante zona de recarga dos aquíferos profundos, havendo a ocorrência de veredas e matas ciliares que devem ser preservadas com vistas à manutenção de sua biodiversidade. No mesmo sentido, o referido plano descreve que o solo da APA possui determinadas características que denotam a predisposição a processos erosivos, havendo, portanto, a necessidade de cuidados especiais quanto ao uso do solo na região.

No ano de $2001 \mathrm{com}$ o intuito de reforçar a proteção da biodiversidade da área, foi criado o Parque Estadual do Lajeado (PEL), com o propósito de proteger amostras dos ecossistemas da Serra do Lajeado, assegurando a preservação de sua flora, fauna, características geológicas, geomorfológicas, e cênicas e também com a finalidade de proteger os mananciais que abastecem a cidade de Palmas, e coibir a expansão urbana nas encostas (NATURATINS, 2016) . Ressalta-se que a área da pesquisa encontra-se totalmente inserida na APA Serra do Lajeado.

Apesar das singularidades e importância ambiental da área, ainda persiste o processo de ocupação fazendo pressão no entorno do Parque Estadual do Lajeado, sendo que atualmente, observa-se a existência de 44 propriedades com diferentes formas de uso, além do (re)parcelamento das propriedades com objetivo de criar condomínios de chácaras, fatos estes que vem gerando maior pressão sobre os aspectos ambientais da área, comprometendo o seu equilíbrio.

A relevância da presente pesquisa se deve ao fato de que a investigação busca analisar como as transformações espaciais, os sujeitos e suas diferentes formas de uso do solo do entorno do Parque Estadual do Lajeado têm ocasionado interferência na conservação ambiental da área.

\section{LOCALIZAÇÃO DA ÁREA DE PESQUISA E PROCEDIMENTTOS METODOLÓGICOS}

\subsection{Localização e caracterização geral da área de es- tudo}

A área da pesquisa corresponde a uma faixa territorial de $3 \mathrm{~km}$ de largura localizada no entorno do Parque estadual do Lajeado, totalizando uma área de 217.31 $\mathrm{Km}^{2}$, que dista cerca de $32 \mathrm{~km}$ da cidade de Palmas, capital do estado do Tocantins. Ressalta-se que para o estabelecimento da área da pesquisa (Figura 1), utilizou-se como base a Resolução Conama n ${ }^{\circ} 428$ de 17 de dezembro de 2010.

Art. $1^{\circ} \mathrm{O}$ licenciamento de empreendimentos de significativo impacto ambiental que possam afetar UC - Unidade de Conservação da Natureza específica ou sua Zona de Amortecimento (ZA), assim considerados pelo órgão ambiental licenciador, com fundamento em Estudo de Impacto Ambiental e respectivo Relatório de Impacto Ambiental (EIA/RIMA), só poderá ser concedido após autorização do órgão responsável pela administração da Unidade de Conservação da Natureza (UC). [...] $\int 2^{\circ}$ Durante o prazo de 5 anos, contados a partir da publicação da Resolução $n^{\circ} 473$, de 11 de dezembro de 2015 (Resolução que alterou o $\$ 2^{\circ}$ da Resolução Conama 428/2010), o licenciamento de empreendimento de significativo impacto ambiental, localizados numa faixa de 3 mil metros a partir do limite da UC, cuja ZA não esteja estabelecida, sujeitar-se-á ao procedimento previsto no caput, [...].(redação dada pela Resolução no 473/2015 (BRASIL. RESOLUÇÃ̃O CONAMA, nº 428, 2010, p.805. negrito nosso e grifo nosso).

Do ponto de vista geomorfológico a área da pesquisa é abrangida pela Serra do Lajeado, conforme descrito por Mantovani (1992, p.6). Nesta área é possível verificar a existência de três feições distintas, sendo elas: as extensas chapadas de topo suavemente ondulado, que delineia o a paisagem por mais de $140 \mathrm{Km}$, desde o município de Monte do Carmo até o município de Tocantínia, 
as margens do rio Tocantins; as áreas escarpadas localizadas no segundo patamar da Serra, apresentando-se acidentada e com declives; e, o piemonte ocidental que se configura como sendo a calha do rio Tocantins.

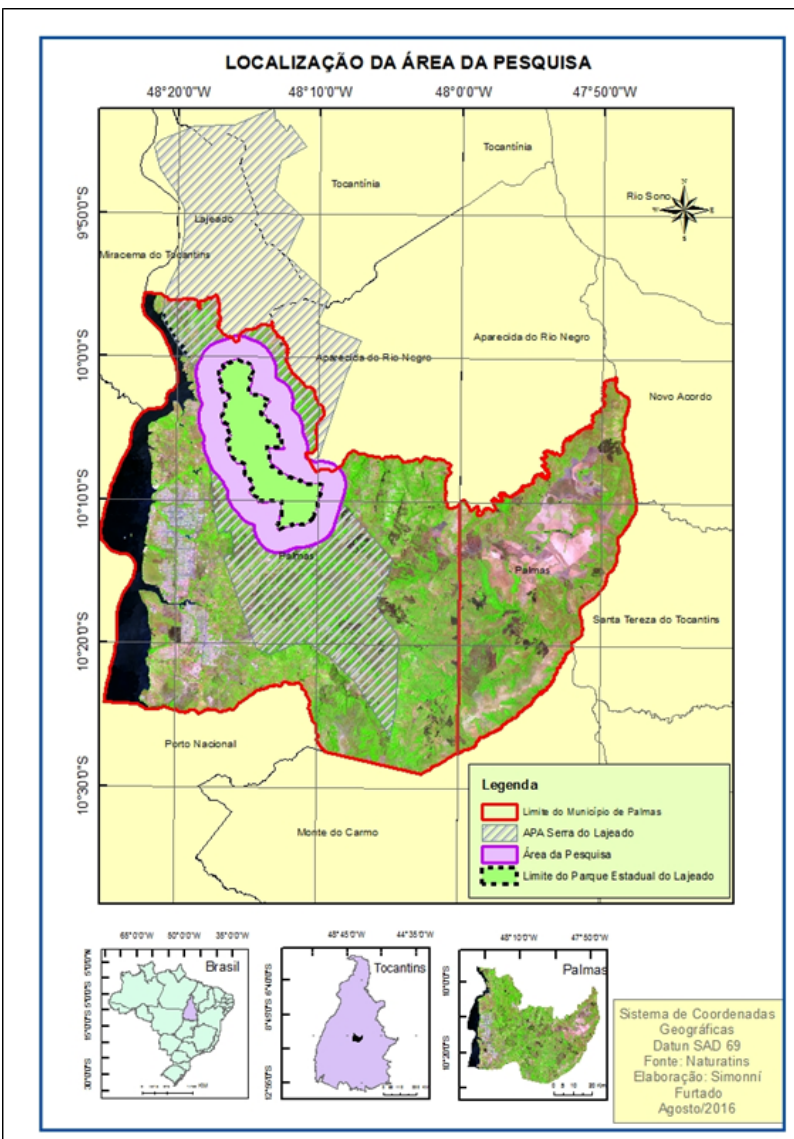

Figura 1- Localização do Parque Estadual do Lajeado Fonte: : Elaboração dos autores

\subsection{Procedimentos Metodológicos}

Para análise das transformações ambientais na área da pesquisa, além do levantamento bibliográfico e documental, que é de praxe, foi realizado o levantamento de material cartográfico por meio de uma ampla pesquisa junto aos órgãos públicos, como Secretaria de Planejamento e Meio Ambiente do Estado do Tocantins (SEPLAN), Instituto Natureza do Tocantins (NATURATINS), Instituto Brasileiro de Geografia e Estatística (IBGE), Instituto Nacional de Pesquisas Espaciais (INPE), entre outros.

Este levantamento torna-se fundamental, principalmente, para o conhecimento e espacialização das informações sobre as transformações evolutivas ocorridas no entorno do Parque Estadual do Lajeado, desde o mo- mento de sua criação, até os dias atuais.

Neste sentido, a presente pesquisa realizou uma análise evolutiva, no período compreendido entre os anos de 2000 a 2015, baseado na utilização de técnicas de sensoriamento remoto com observações de imagens satélites. As imagens satélites e os respectivos sensores utilizados na referida análise, podem ser observados na tabela 1.

Tabela 1 - Características dos Satélites, Sensores e Imagens

\begin{tabular}{c|c|c|c|c}
\hline ANO & $\mathbf{2 0 0 0}$ & $\mathbf{2 0 0 5}$ & $\mathbf{2 0 1 0}$ & $\mathbf{2 0 1 5}$ \\
\hline Satélite & Landsat 5 & Landsat 5 & Landsat 5 & Landsat 8 \\
\hline Sensor & $\begin{array}{c}\text { Thematic Mapper } \\
\text { (TM) }\end{array}$ & $\begin{array}{c}\text { Thematic Mapper } \\
\text { (TM) }\end{array}$ & $\begin{array}{c}\text { Thematic Mapper } \\
\text { (TM) }\end{array}$ & $\begin{array}{c}\text { Thematic Mapper } \\
\text { (TM) }\end{array}$ \\
\hline Data & $14 / 06 / 2000$ & $14 / 07 / 2005$ & $14 / 09 / 2010$ & $28 / 07 / 215$ \\
\hline Cenas/orbita & 222 & 222 & 222 & 222 \\
\hline Ponto & 067 & 067 & 067 & 067 \\
\hline $\begin{array}{c}\text { Resolução } \\
\text { espacial }\end{array}$ & $30 \mathrm{~m}$ & $30 \mathrm{~m}$ & $30 \mathrm{~m}$ & $30 \mathrm{~m}$ \\
\hline $\begin{array}{c}\text { Composição } \\
\text { RGB }\end{array}$ & 543 & 543 & 543 & 654 \\
\hline
\end{tabular}

Fonte: : Elaboração dos autores

Os arquivos digitais (formato vetorial) foram cedidos pela Secretaria de Planejamento e Meio Ambiente do Estado do Tocantins - SEPLAN e pelo Instituto $\mathrm{Na}$ tureza do Tocantins - NATURATINS. Por meio desses arquivos foi possível identificar a área do Parque Estadual do Lajeado, bem como, definir o limite de $3 \mathrm{~km}$ no entorno do mesmo como área de estudo. Esses arquivos possibilitaram, também, a localização e identificação das propriedades rurais, hidrografia, rodovias, entre outros aspectos.

Obtiveram-se, ainda, arquivos digitais de mapas temáticos pré-existentes, cedidos pelo Instituto de Terras do Estado do Tocantins - ITERTINS. Por meio deste foi possível observar organização fundiária, da área da pesquisa, anterior ao ato de criação da Unidade de Conservação da Natureza em pesquisa, o Parque Estadual do Lajeado.

Utilizou-se também, a carta topográfica Vila Canela (Folha SC-22-Z-B III, MI 1544), da Diretoria de Serviço Geográfico do Exército - DSG, na escala 1:100.000 do ano de 1979, a qual serviu como mapa base.

Destaca-se a realização das atividades em campo percorrendo-se diversos caminhos e estradas da área de pesquisa, utilizando-se veículos motorizados para locomoção, receptor de navegação, do Sistema de Posicionamento Global - GPS para espacialização das informações e máquina fotográfica digital para descrição ambiental da área, bem como, dos aspectos de uso do solo. 
Para manipulação e confecção dos produtos cartográficos realizados na pesquisa, foi utilizado como ferramenta básica o Sistema de Informações Geográficas - SIG. É importante salientar que a utilização desta tecnologia envolveu dados georreferenciados que foram armazenados, em um banco de dados possibilitando sua manipulação e análise espacial.

Os trabalhos cartográficos foram desenvolvidos no Laboratório de Geoprocessamento do Curso de Geografia da Universidade Federal do Tocantins (LABGEOP), envolvendo de maneira geral, quatro etapas:

$\mathrm{Na}$ primeira etapa foi realizada a organização de um banco de dados via Sistema de Informação Geográfica - SIG, o software Spring (versão 5.1.8) do Instituto nacional de Pesquisas Espaciais - INPE, para a inserção de dados e posterior manipulação.

$\mathrm{Na}$ segunda etapa, foi realizado o recorte da carta topográfica, seguindo uma faixa circundante de $3 \mathrm{~km}$ do limite do Parque Estadual do Lajeado, para posterior extração de dados como a drenagem, toponímias, entre outros.

$\mathrm{Na}$ terceira etapa, após tentativa de uma classificação supervisionada para elaboração dos mapas de uso do solo dos anos de 2000, 2005, 2010 e 2015, realizou-se a vetorização manual das diferentes classes de uso, com base na visualização das imagens de satélites.

$\mathrm{Na}$ quarta etapa, foram analisadas as transformações espaciais ocorridas na área de estudo, por meio das imagens de satélite dos anos de 2000 a 2015, bem como, realizou-se à mensuração comparativa das classes de uso do solo, além do desenvolvimento de diversos trabalhos de campo com levantamento fotográfico da área.

\section{ANÁLISE DAS TRANSFORMAÇÕES AM- BIENTAIS NO ENTORNO DO PARQUE ES- TADUAL DO LAJEADO ENTRE OS ANOS DE 2000 A 2015}

Quanto as transformações ambientais ocorridas na área de pesquisa, podem ser observados os referidos mapas de uso do solo (anos de 2000 a 2015) com os quais percebeu-se que no ano de 2000 (Figura 2) cerca de 46\% da área apresentava cobertura vegetal natural de cerrado frente aos 54\% das áreas de urbanização e agropecuária, conforme (Gráfico 1).

Ainda referente ao ano de 2000, foi possível observar as transformações de uso do solo e consequentemente do ambiente local, onde a supressão da cobertura vegetal ocorreu de forma difusa.

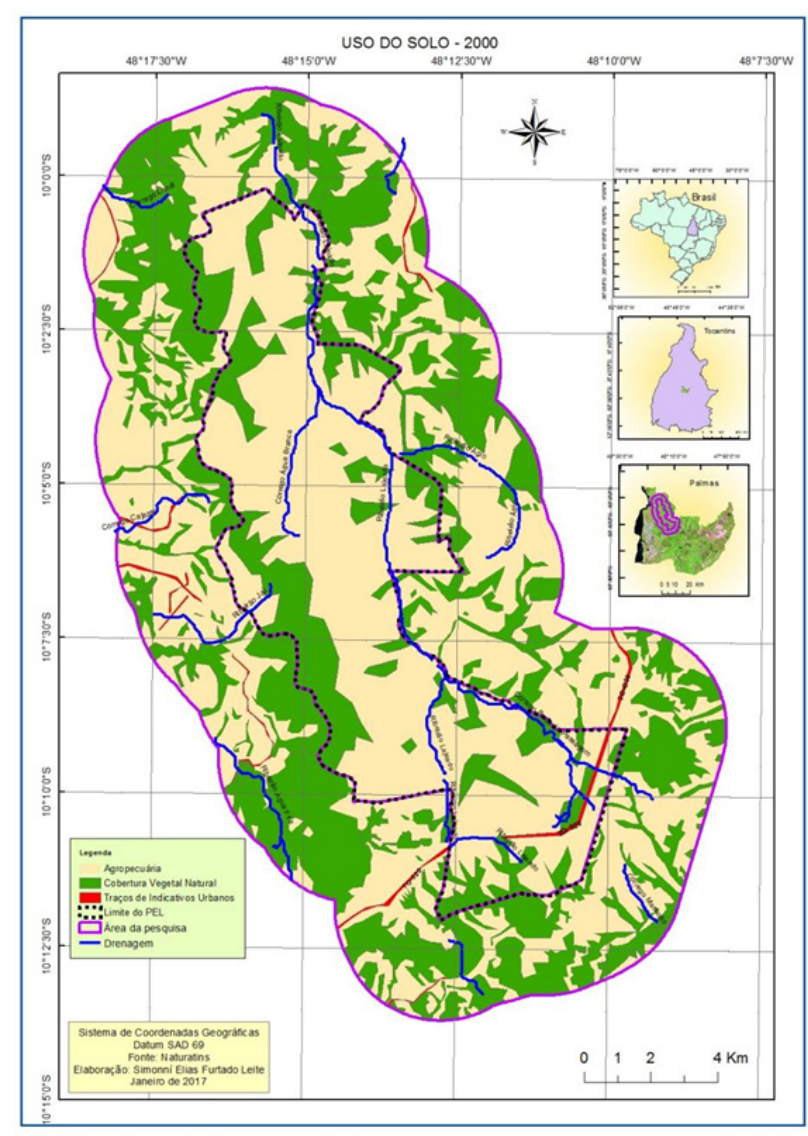

Figura 2 - Uso do Solo no Entorno do Parque Estadual do Lajeado no ano de 2000

Fonte: : Elaboração dos autores

Uso do solo no entorno do PEL- 2000

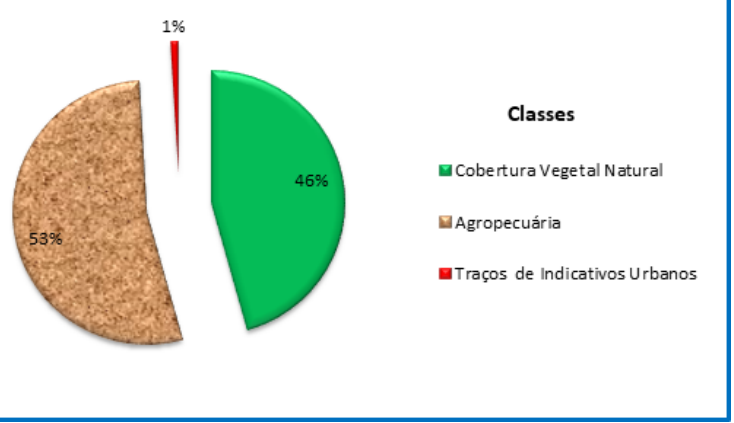

Gráfico 1 - Classes de uso do solo da área de pesquisa no ano de 2000 Fonte: : Elaboração dos autores

Porém, cabe-se destacar que, as áreas com maior presença de indicativos urbanos, denotaram maior interferência direta na supressão localizada da cobertura vegetal, no entanto, este fator não é regra, pois se observa que o processo de ocupação da região, também, foi preponderante nas transformações espaciais da área. 
Ainda neste sentido, observou-se que a expansão do uso agropecuário apresentou maior relevância, em razão da ocupação histórica local ter ocorrido pela implantação da atividade agropecuária extensiva.

Neste contexto, constatou-se que o uso agropecuário correspondeu a 53\% da área, já no que diz respeito à presença de indicativos urbanos, tais como estradas $\mathrm{e}$ demarcações de loteamentos, corresponderam a 1\% da área. Ressalta-se que os indicativos urbanos mais evidentes se apresentam na porção oeste da área de estudo, o que reflete o processo de expansão urbana no entorno da cidade de Palmas.

Assim, verifica-se que as transformações espaciais, de uso do solo, no entorno do Parque Estadual do Lajeado, no ano de 2000, foi principalmente em decorrência da ocupação histórica da localidade advinda da existência de grandes propriedades voltadas à pecuária extensiva Teixeira (2009 p. 91-99).

Ressalta-se que essa ocupação histórica refletiu, demasiadamente, para as transformações de uso do solo, não só na área da pesquisa, como também, na área, hoje, abrangida pelo Parque Estadual do Lajeado. Neste sentido é oportuno evidenciar alguns aspectos de motivação jurídica que contradiz com a realidade da área definida como sendo uma unidade de conservação da natureza de Proteção Integral.

A motivação para a criação do parque ocorreu, teoricamente, sobre dois aspectos; primeiro devido à natureza jurídica da Área de Proteção Ambiental - APA Serra do Lajeado, que conforme já mencionado anteriormente, caracteriza-se pelo uso sustentável dos recursos naturais, havendo menos rigor nas medidas protetivas de caráter ambiental; segundo devido à necessidade de compensação ambiental para os impactos decorrente do processo de implantação da Usina Hidrelétrica Luiz Eduardo Magalhães.

Na prática, porém, a implantação de uma Unidade de Proteção Integral, cuja natureza jurídica, não permite o uso sustentável dos recursos naturais, contradiz com as condições naturais da área escolhida, haja vista que um ano antes da criação do parque, essa área já apresentava mais de $70 \%$ da sua cobertura vegetal natural suprimida, conforme pode ser observado na tabela 2 .

Neste contexto, a lógica que motivou a criação do parque, no sentido de proteger exemplares naturais como forma de compensação do que seria devastado com a implementação da usina hidrelétrica Luiz Eduardo Magalhães foi no mínimo equivocada, pois a área escolhida apresentava-se severamente alterada.
Tabela 2 - Uso do solo na área pertencente ao Parque Estadual do Lajeado - PEL no ano de 2000

\section{Uso do solo na área do Parque Estadual do Lajeado em 2000}

\begin{tabular}{l|r|c}
\hline & \multicolumn{1}{|c|}{$\mathrm{Km}^{2}$} & \multicolumn{1}{c}{$\%$} \\
\hline Cobertura Vegetal Natural & 27,16 & 25.22 \\
\hline Agropecuária & 79,86 & 74.18 \\
\hline Traços de Indicativos Urbanos & 0,64 & 0.59 \\
\hline & & \\
\hline
\end{tabular}

Fonte: : Elaboração dos autores

Por outro lado, é indiscutível que o ato de criação do parque permitiu a conservação da localidade como um todo, possibilitando o início da regeneração dos aspectos naturais da área escolhida para se constituir a Unidade de Conservação de Proteção Integral, ou seja, o Parque Estadual do Lajeado.

$\mathrm{Na}$ análise dos aspectos de uso do solo na área da pesquisa, no ano de 2005, constatou-se a continuidade das transformações ocorridas no período anterior, conforme pode ser verificada no (Figura 3).

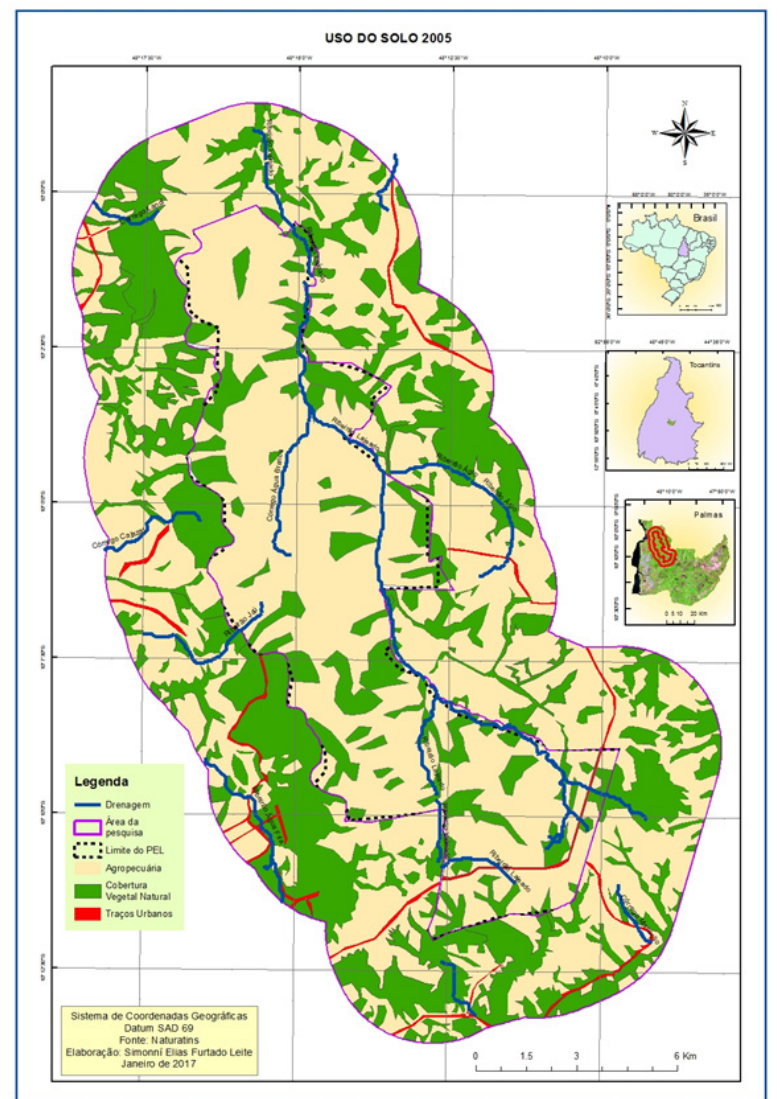

Figura 3 - Uso do Solo no Entorno do Parque Estadual do Lajeado no ano de 2005

Fonte: : Elaboração dos autores 
Observando a figura 3 referente ao uso do solo do ano de 2005, verificou-se uma perda da cobertura vegetal em relação ao ano de 2000 de um pouco mais de $6 \mathrm{Km}^{2}$, correspondendo a supressão de cerca de $7 \%$.

É importante enfatizar que a criação da unidade de proteção integral, neste caso, o Parque Estadual do Lajeado, por sua natureza jurídica, não permite a presença de populações, em sua área. Neste contexto, a pressão exercida no parque em razão da ocupação da localidade, foi desviada para o entorno do mesmo, constituindo-se assim, em mais um fator de pressão que corroborou para a retirada da cobertura vegetal natural na a área da pesquisa.

Em relação à presença de traços de indicativos urbanos, o mapeamento de uso do solo do ano de 2005, revelou a continuidade da pressão ocorrida na porção oeste, fruto da expansão urbana da cidade de Palmas, bem como, evidenciou o aumento da presença de traços de indicativos urbanos nas porções sul e leste da área da pesquisa.

Considerando-se ainda a supressão da cobertura vegetal natural no ano de 2005, o que mais chamou a atenção foi à porção nordeste, nesta, observou-se uma considerável retirada da cobertura vegetal, sendo que ao confrontar os dados da referida área com a perda da cobertura vegetal natural em toda a extensão da área da pesquisa, que apresentou redução de cerca de $3 \%$, conforme gráfico 2 , verifica-se que na porção nordeste ocorreu a maior supressão.

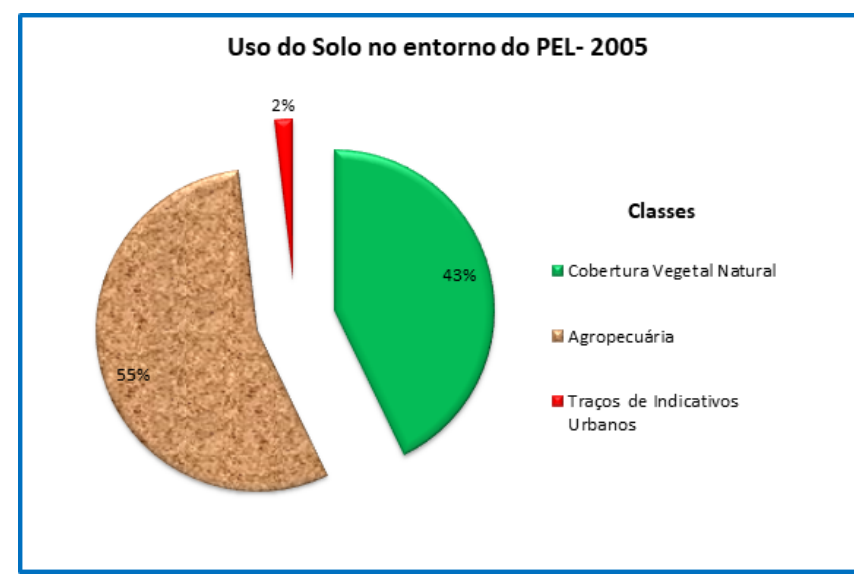

Gráfico 2 - Classes de uso do solo da área de pesquisa no ano de 2005 Fonte: : Elaboração dos autores

Ao analisar, somente a porção norte da área de pesquisa, foi possível observar que em 2000, havia cerca de $15,84 \mathrm{Km}^{2}$ de cobertura vegetal natural e no ano de 2005 essa cobertura apresentou uma redução de 30,61\% restando somente, $4,85 \mathrm{~km}^{2} \mathrm{da}$ área.

É oportuno ressaltar que, in loco, verificou-se a presença de áreas destinadas à produção agrícola e propriedades com tanques de piscicultura presentes nesta porção, justificando-se, assim a observação da elevada supressão da cobertura vegetal natural local.

Na análise de 2010 verificou-se que ocorreu uma intensa supressão da cobertura vegetal natural na porção oeste da área da pesquisa, reflexo da continuidade do processo de (re)parcelamento de antigas propriedades rurais nesta porção. Concomitantemente ao (re)parcelamento ocorreu à abertura de condomínios de chácaras, vias de acesso aos condomínios e estruturas de eletrificação, fatos estes que proporcionaram maior transformação ambiental, conforme pode ser observado na figura 4.

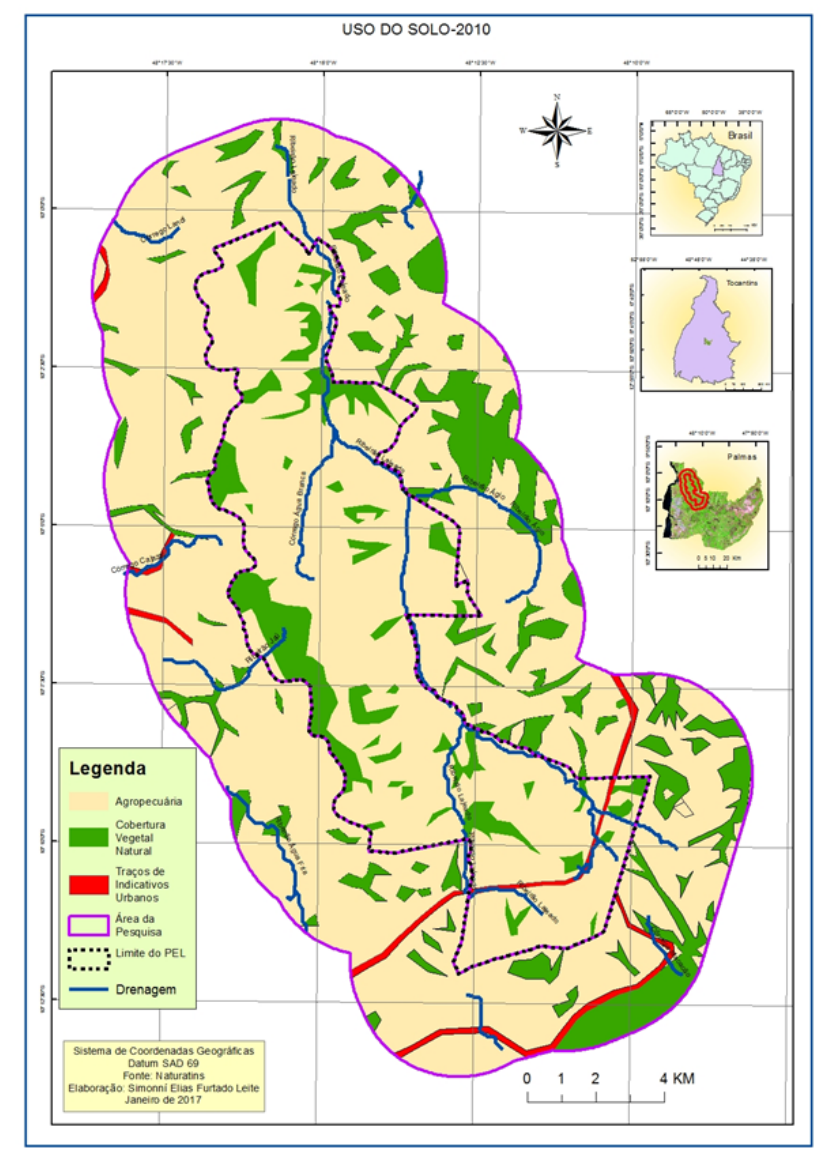

Figura 4 - Uso do Solo no Entorno do Parque Estadual do Lajeado no ano de 2010

Fonte: : Elaboração dos autores

Ainda neste ano, observou-se que a cobertura vegetal natural da área de pesquisa correspondia a apenas 17\%, já que predominantemente $81 \%$ da área eram destinadas à agropecuária. Quanto aos traços de indicativos urbanos continuava correspondendo a $2 \%$, conforme podem ser observado no gráfico 3.

É importante observar, também, algumas transformações ocorridas no Parque Estadual do Lajeado, haja vista 
que toda e qualquer alteração ocorrida na área da pesquisa invariavelmente, iria interferir na área do parque e vice versa.



Gráfico 3 - Classes de uso do solo da área de pesquisa no ano de 2010 Fonte: : Elaboração dos autores

Diante do exposto, salienta-se que no que diz respeito ao uso do solo da área destinada ao Parque Estadual do Lajeado, que a mesma, em 2000, ano de sua criação, já se encontrava profundamente alterada, pois conforme mencionado anteriormente, esta área pertencia a três grandes propriedades, cujo uso do solo era voltado para a atividade da pecuária extensiva SEPLAN (2005). Neste contexto, grande parte da cobertura vegetal natural, já havia sofrido alterações.

Ao analisar-se resumidamente a evolução do uso do solo referente à cobertura vegetal natural entre 2000 a 2015 (Tabela 3), observa-se que no ano de 2000, havia, somente, 27,16 $\mathrm{Km}^{2}$ de cobertura vegetal; entre os anos de $2000 \mathrm{a}$ 2005, a cobertura vegetal apresentou uma redução de 4,78 $\mathrm{Km}^{2}$; entre os anos de 2005 a 2010, essa redução foi de 4,04 $\mathrm{Km}^{2}$; já entre os anos de 2010 a 2015, observou-se uma redução na supressão da cobertura vegetal de $0,49 \mathrm{Km}^{2}$.

Figura 6 - Espacialização da transição de cobertura florestal no período de 1985 a 2014. O gráfico no modo "pizza” indica as perdas e ganhos em $\mathrm{km}^{2}$ para o período analisado (1985-2014)

\begin{tabular}{|c|c|c|c|c|c|c|}
\hline \multicolumn{7}{|c|}{ a Vegetal Natural (SVC) na Área do Parque Estadual do Lajeado } \\
\hline & \multirow[b]{2}{*}{ SCVN Km² } & \multirow[b]{2}{*}{$\begin{array}{l}\text { Média da SCVN } \\
\text { dos } 4 \text { periodos } \\
\text { analisados } \mathrm{Km} 2\end{array}$} & \multicolumn{3}{|c|}{$\begin{array}{l}\text { Incremento da SCVN* entre os periodo } \\
\qquad \mathrm{Km}^{2}\end{array}$} & \multirow{2}{*}{$\begin{array}{c}\text { Média do } \\
\text { incremento da } \\
\text { SCVN entre os } \\
\text { periodos, em um } \\
\text { prazo de } 5 \text { em } 5 \\
\text { anos } \mathrm{Km}^{2}\end{array}$} \\
\hline & & & 2000-2005 & 2005-2010 & 2010-2015 & \\
\hline & 27.16 & \multirow{4}{*}{21.43} & \multirow{4}{*}{4.78} & \multirow{4}{*}{4.04} & \multirow{4}{*}{0.49} & \multirow{4}{*}{3.10} \\
\hline 20055 & 22.38 & & & & & \\
\hline 20104 & 18.34 & & & & & \\
\hline 2015 & 17.85 & & & & & \\
\hline
\end{tabular}

*SCVN - Supressão da Cobertura Vegetal Natural.

Fonte: : Elaboração dos autores

Assim, pode-se verificar que somente após quase dez anos da criação do Parque Estadual do Lajeado, é que percebeu-se uma redução da supressão da cobertura vegetal natural, isto possivelmente, em razão das medidas protetivas direcionadas para área. Desta maneira, compreende-se o ocorrido, a luz do pensamento de Cunha (2012, p. 27 - 28), quando descreve que, em outras palavras, que o ato da criação de uma unidade de conservação da natureza, não garante a efetividade da proteção dos recursos naturais ali existentes, mesmo tendo sua importância reconhecida.

Em continuidade da análise, em 2015, verificou-se que a cobertura vegetal natural correspondia a 20,06\%, as áreas de uso agropecuário totalizavam $77,43 \%$ e as áreas com a presença de traços de indicativos urbanos cobriam uma extensão de 2,64\% da área. De um modo geral pode-se observar que em 2015 as transformações ambientais tiveram uma significativa contribuição urbana, fato este notado pela observação do aumento de parcelamentos e (re)parcelamentos de propriedades rurais, principalmente, na porção oeste da área da pesquisa, conforme pode ser observado nas figuras 5 e 6 .

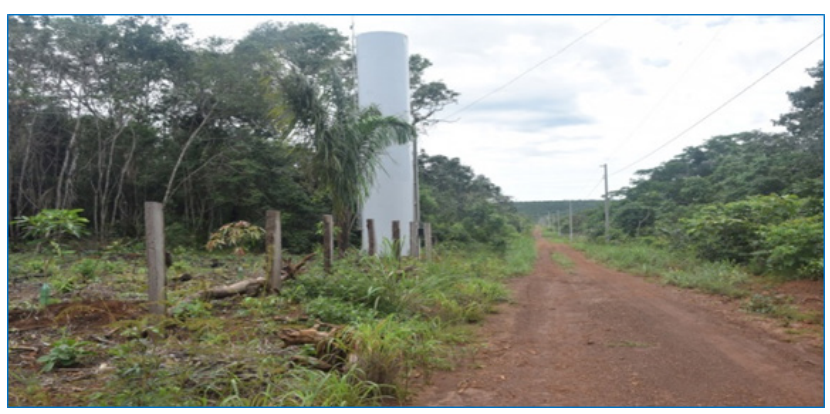

Figura 5 - Visualização de traços de indicativos urbanos com (re)parcelamento de antigas propriedades, loteamento Sonho Verde

Fonte: : Acervo dos autores

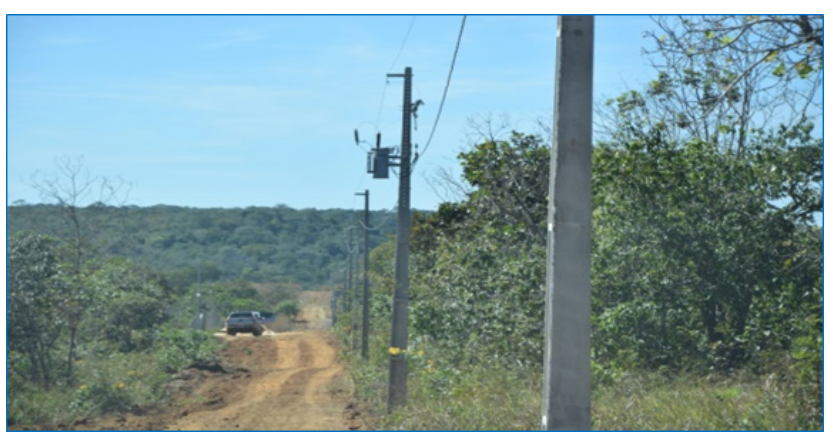

Figura 6 - Visualização de traços de indicativos urbanos com abertura de vias de acesso e postes para eletrificação aos loteamentos localizados na porção sudoeste da área da pesquisa Fonte: : Acervo dos autores

A forte presença de parcelamentos e (re)parcelamentos de antigas propriedades na área da pesquisa, 


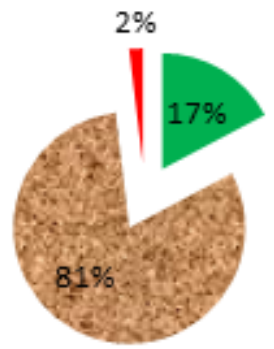

Classes
Cobertura Vegetal
Natural
Agropecuária
Traços de
Indicativos Urbanos

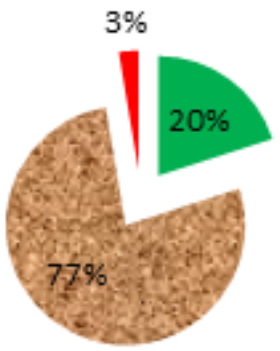

Classes
— Cobertura Vegetal
Natural
Agropecuária
Traços de Indicativos
Urbanos

Figura 7- Comparativo dos dados do uso do solo na área de pesquisa entre os anos de 2010 e 2015

Fonte: : Elaboração dos autores

revela que o Parque Estadual do Lajeado não possui claramente definido, uma zona de amortecimento, DBO-Engenharia/Naturatins (2005). Neste sentido, o único dispositivo legal que limita a degradação ambiental da área da pesquisa, constitui-se no artigo $1^{\circ}$ da resolução do Conselho Nacional do Meio Ambiente - CONAMA 428/2010, sendo este dispositivo responsável pela exigência de licenciamento ambiental a qualquer atividade e/ou empreendimento que possa ocasionar alterações ambientais na área de $3 \mathrm{Km}$ circundante a unidade de conservação.

Observando-se a figura 7, mostrando os gráficos de 2010 e 2015, é possível inferir que neste período, ocorreu um incremento da cobertura vegetal natural na área de pesquisa em aproximadamente $2,76 \%$, visto que em 2010 correspondia a 17\% da área e no ano de 2015 passou a $20 \%$.

Já em relação ao uso agropecuário, observou-se que no ano de 2010 abrangia cerca de $81 \%$ da área, sendo que, cinco anos depois, passou a representar somente $77 \%$ da área, logo houve uma redução de 3,59\%. No que diz respeito à presença de traços de indicativos urbanos observou-se um incremento de $0,74 \%$.

No mesmo sentido na figura 8, observa-se a espacialização do uso do solo na área da pesquisa no ano de 2015, onde pôde-se observar que na porção sul ocorreu a supressão da cobertura vegetal natural em razão da instalação de chacareiros, o que desencadeou um processo de (re)parcelamento da área e na porção sudoeste, foi possível constatar a existência de novos (re)parcelamentos, sendo estes, visualizados na imagem de satélite e confirmados em trabalhos de campo.

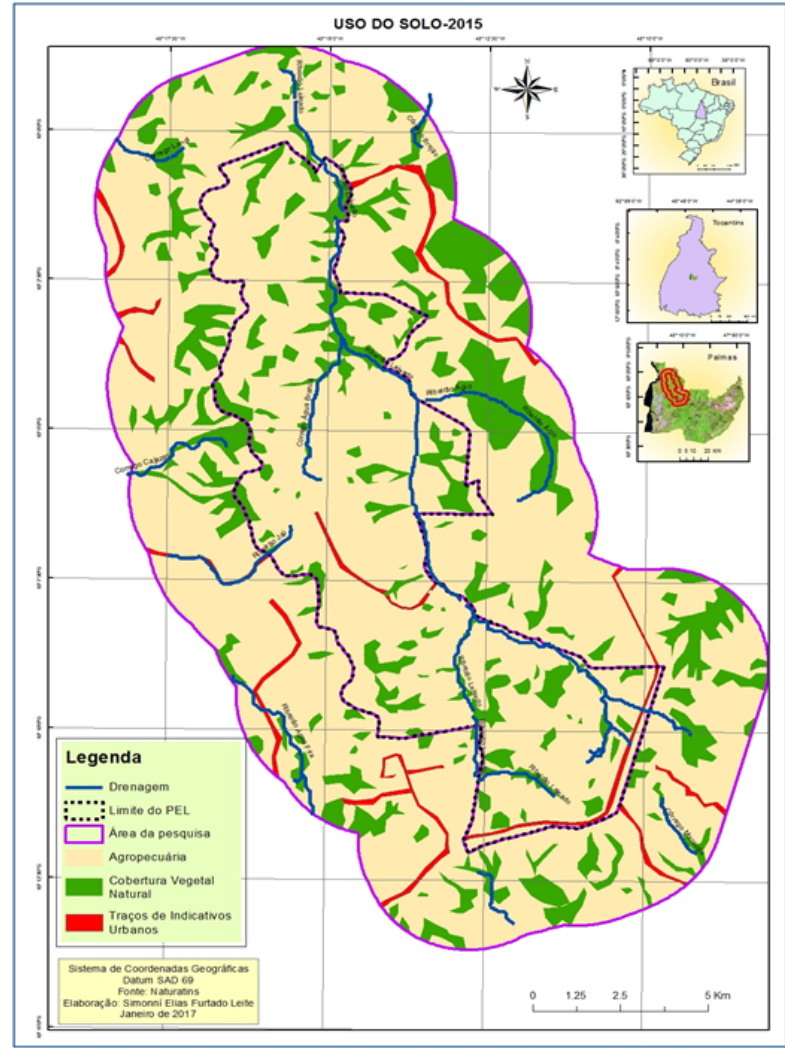

Figura 8 - Uso do Solo no Entorno do Parque Estadual do Lajeado no ano de 2015

Fonte: : Elaboração dos autores

No mesmo sentido, constatou-se que no limite sudoeste do Parque Estadual do Lajeado, está sendo estruturada uma área com 129 lotes de $5.000 \mathrm{~m} 2$, cada lote, denominado Loteamento Sonho Verde, conforme pode ser observado na figura 9. 


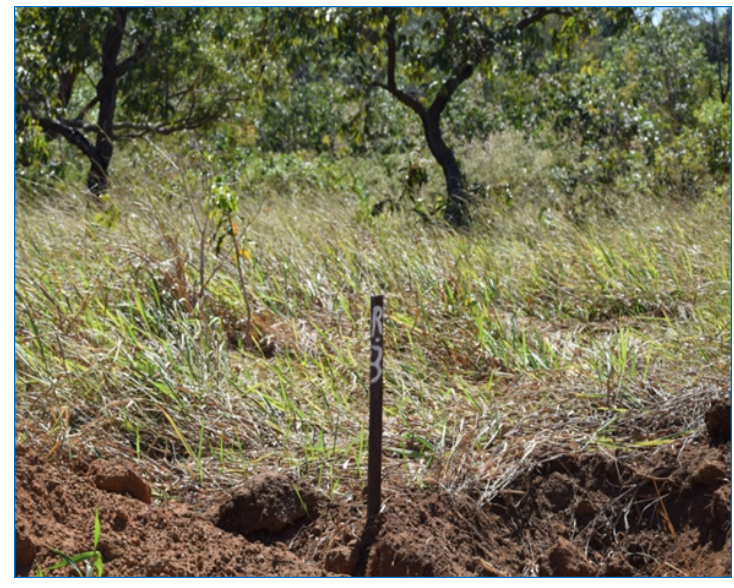

Fotografia 9 - Área com demarcação de loteamentos em primeiro plano e em segundo plano observa-se a presença da cobertura vegetal natural de cerrado

Fonte: : Acervo dos autores

Em se tratando do uso do solo em uma unidade de conservação de proteção integral, o caso do Parque Estadual do Lajeado, é oportuno ressaltar, que mesmo diante das medidas protetivas pertinentes a essa categoria de unidade, o estudo revela pequenas alterações de uso entre os anos de 2010 e 2015, conforme tabela 4.

Tabela 4 - Comparativo do Uso do solo no Parque Estadual do Lajeado entre os anos de 2010 e 2015

\begin{tabular}{|c|c|c|c|}
\hline \multicolumn{4}{|c|}{ Uso do solo no Parque Estadual do Lajeado } \\
\hline \multirow[b]{2}{*}{ Ano } & & CLASSES & \\
\hline & $\begin{array}{l}\text { Cobertura Vegetal } \\
\text { Natural }(\%)\end{array}$ & $\begin{array}{c}\text { Agropecuária* } \\
\text { (\%) }\end{array}$ & $\begin{array}{l}\text { Traços de Indicativos } \\
\text { Urbanos } \\
\text { (\%) }\end{array}$ \\
\hline 2010 & 17,04 & 82,19 & 0,77 \\
\hline 2015 & 16,58 & 82,15 & 1,23 \\
\hline \multicolumn{4}{|l|}{ Alteraçöes: } \\
\hline $\begin{array}{rr} & \text { Incremento } \\
& \text { Redução }\end{array}$ & 0,46 & 0,03 & 0,46 \\
\hline
\end{tabular}

Fonte: : Elaboração dos autores

A redução da cobertura vegetal natural, expressada na tabela 4, é justificada por dois fatores observados em campo: o primeiro está relacionado aos incêndios florestais ocorridos no entorno do Parque Estadual do Lajeado e que se alastraram para algumas áreas do parque suprimindo a cobertura vegetal natural; o segundo está relacionado à expansão de uso e ocupação do entorno do parque com avanço sobre seus limites, a exemplo da presença de tanques de piscicultura na porção nordeste do parque.

Geografia, Ensino \& Pesquisa, Vol. 22 (2018), e13, p. 01-11

ISSN: 2236-4994 DOI: 10.5902/2236499429699

\section{CONSIDERAÇÕES FINAIS}

A presente pesquisa revelou diversos aspectos relacionados ao uso do solo da área correspondente ao entorno do Parque Estadual do Lajeado, dentre eles, dois se apresentaram com maior expressividade: a expansão da agricultura em larga escala na porção leste e sudeste, e, a expansão dos condomínios de chácaras na porção oeste e sudoeste.

A expansão da agricultura em larga escala caracteriza-se pelo inverso do que ocorre em relação à expansão dos condomínios de chácaras, pois estes são frutos de um (re)parcelamento de antigas propriedades; já a agricultura em larga escala está na contramão deste processo, pois observou-se que ocorre o arrendamento ou compra de pequenas propriedades para viabilizar o plantio em grandes áreas.

Neste contexto, o caráter da agricultura em larga escala nas porções leste e sudeste da área da pesquisa, bem como, dos condomínios de chácaras vêm promovendo perturbações e degradação ambiental que atingem direta ou indiretamente o Parque Estadual do Lajeado. Sendo oportuno ressaltar que o uso do solo no entorno do PEL, seja pelos condomínios de chácaras ou pela agricultura em larga escala estão ocorrendo com o aval do poder publico competente.

Ainda foi possível observar que o uso do solo para a agricultura em larga escala, em razão da necessidade de áreas cada vez maiores para o plantio, tem promovido à supressão acelerada da cobertura vegetal natural, ocasionando o comprometimento dos mananciais hídricos que abastecem importantes rios na localidade, como também, a supressão das matas ciliares.

No que diz respeito ao (re)parcelamento de antigas propriedades, sendo transformadas em condomínios de chácaras, localizados, principalmente, nas porções oeste e sudoeste, da área da pesquisa, e que em muitos casos, fazem limite com a unidade de conservação Parque Estadual do Lajeado, observou-se que estes geram perturbações e degradação no entorno do parque, visto que, o referido (re)parcelamento , também gera a supressão da cobertura vegetal natural, para que os proprietários possam fazer suas "benfeitorias".

Outro agravante do (re)parcelamento, observado em campo, refere-se à escavação de poços semiartesianos para abastecimento dos lotes dos condomínios, como por exemplo, dos 129 lotes existentes em apenas 
um dos condomínios observados na localidade; o que consequentemente promoverá o rebaixamento do lençol freático, comprometendo os recursos hídricos da área da pesquisa.

Em ambos os casos, seja na agricultura em larga escala ou no (re)parcelamento das propriedades, infere-se como agravante, a legislação vigente relativa à área destinada à reserva legal (Código Florestal Brasileiro, Lei $\left.\mathrm{n}^{\mathrm{o}} 12.651 / 2012\right)$, que diz que a área destinada à reserva legal poderá ser compensada em outra localidade que não pertença, necessariamente, a propriedade privada, em si, onde ocorreu a supressão da cobertura vegetal natural.

Com esta lacuna da legislação, os proprietários, sejam eles condôminos ou agricultores estão promovendo a supressão da cobertura vegetal natural da área da pesquisa, amparados legalmente.

Em se tratando dos indicativos de traços urbanos, a pesquisa revelou que esta foi à única classe que apresentou um acréscimo no período de 2010 a 2015. Este fato chamou atenção, pois é fruto do processo de expansão urbana observado na localidade, quanto mais loteamentos, mesmo que ainda não tenha ocorrido à supressão da cobertura vegetal natural para a instalação de benfeitorias, ocorrerá mais abertura de vias de acesso na área.

Vale lembrar que uma das maiores infraestrutura de acesso desenvolvida na região refere-se ao acesso do monumento "Cristo" que está sendo erguido no Morro do Chapéu, localizado na área da presente pesquisa.

Por fim, o desenvolvimento da pesquisa revelou que no estado do Tocantins, bem como, em todo território nacional, prevalece à vontade política, que vai ao encontro dos interesses econômicos, em detrimento dos interesses ambientais.

Neste contexto, toda e qualquer política de cunho ambiental esbarra, sempre, nas questões econômicas, e que infelizmente, os governos, sejam eles federal, estadual ou municipal, estão atrelados às organizações econômicas supranacionais, relegando para segundo plano as políticas de cunho ambiental.

Diante do exposto, infere-se que o gestor de uma unidade de conservação da natureza está condicionado às influências da política governamental vigente, situação esta que deve ser repensada para que as ações de conservação sejam realmente eficazes e desenvolvidas em continuidade.

\section{REFERÊNCIAS}

BRASIL. Lei $\mathrm{n}^{\circ} \mathbf{9 . 9 8 5}$, de 18 de julho de 2000. Regulamenta o art. 225, \10, incisos I, II, III e VII da Constituição Federal, institui o Sistema Nacional de Unidades de Conservação da Natureza e dá outras providências. Lex: Coleção de Leis do Brasil, Brasilia, v. 7, p. 4917,2000.

BRASIL. Lei $\mathrm{n}^{\circ}$ 12.651, de 25 de maio de 2012. Dispõe sobre a proteção da vegetação nativa; altera as Leis $\mathrm{n}^{\circ} \mathrm{s}$ 6.938, de 31 de agosto de 1981, 9.393, de 19 de dezembro de 1996, e 11.428, de 22 de dezembro de 2006; revoga as Leis nos 4.771, de 15 de setembro de 1965, e 7.754, de 14 de abril de 1989, e a Medida Provisória n ${ }^{\circ}$ 2.166- 67, de 24 de agosto de 2001; e dá outras providências. Diário Oficial [da] República Federativa do Brasil, Poder Executivo, Brasilia, DF. Seção 1 - 28 mai. 2012, p. 1.

BRASIL. Resolução CONAMA no 428 de 17 de dez. 2010. Dispõe, no âmbito do licenciamento ambiental sobre a autorização do órgão responsável pela administração da Unidade de Conservação (UC), de que trata o $\ 3^{\circ}$ do artigo 36 da Lei n ${ }^{\circ} 9.985$ de 18 de julho de 2000, bem como sobre a ciência do órgão responsável pela administração da UC no caso de licenciamento ambiental de empreendimentos não sujeitos a EIA-RIMA e dá outras providências. Diário Oficial [da] República Federativa do Brasil, Poder Executivo, Brasilia, DF, Seção 1 - 20 dez. 2010, p. 805.

CUNHA, C. F. Conflitos fundiários no Parque Estadual do Rio Negro Setor Sul. 2012. Dissertação (Mestrado) - Programa de Pós-Graduação em Gestão de Áreas Protegidas Na Amazônia, MPGAP/INPA, Manaus -AM.

\section{DIEGUES, A. C. O Mito Moderno da Natureza Into-} cada. São Paulo: Hucitec, 2000, p. 161.

DSG, Diretoria de Serviço Geográfico do Exército (Brasília, DF). Carta Topográfica. Vila Canela,1979. 1 Carta topográfica. Escala 1:100.000. Folha SC-22-Z-B III, MI 1544.

MANTOVANI, L. E. Avaliação do meio físico da Reserva Ecológica da Serra do Lajeado, região de Palmas, Tocantins. In: MIRANDA, J.R., MANTOVANI, E., SANTOS R. Z., COUTINHO, A. C., MANGABEIRA, J. A. C. (Eds.). Mapeamento ecológico da Reserva do Lajeado (TO). Campinas: EMBRAPA; NMA, 1992. p.6 
TEIXEIRA, L.F.C. A formação de Palmas. Revista UFG, Goiânia, n. 6, jun, 2009. p. 91-99.

TOCANTINS (Estado). Instituto Natureza do Tocantins - NATURATINS. Plano de Manejo da APA Serra do Lajeado. 2003, p. 25.

TOCANTINS (Estado). Secretaria de Planejamento - SEPLAN/ DBO ENGENHARIA. Plano de Manejo Parque Estadual do Lajeado, Goiânia, 2005, p. 32.

TOCANTINS. Decreto $\mathbf{n}^{\circ} \mathbf{2 1 3}$ de 14 de fev. 1989. Dispõe sobre os limites geográficos da Área de Representação Ecológica Serra do Lajeado (ARESL); e dá outras providências. Diário Oficial do Estado do Tocantins, Poder Executivo, Palmas, TO. Seção 1 - 16 de fev. 1989, p. 33.

\section{Correspondência dos autores:}

Simonní Elias Furtado e-mail: simonnifurtado@gmail.com Sandro Sidnei Vargas de Cristo e-mail: sidneicristo@mail.uft.edu.br

Artigo recebido em: 26/10/2017

Revisado pelos autores em: 07/12/2017

Aceito para publicação em: 15/12/2017 